\title{
ANALYSIS OF THE CONNECTION BETWEEN PAIN, DISABILITY AND A RADIOLOGICAL IMAGE DETERMINING THE TREATMENT PROCESS
}

\author{
Grzegorz Mańko ${ }^{1)}$, Anna Kuśnierczyk ${ }^{2}$, Magdalena Pieniążek ${ }^{3)}$, Wojciech Kurzydło ${ }^{4)}$ \\ 1) Institute of Exercise Ergonomy and Physiology, Department of Health Sciences of the Jagiellonian University Collegium Medicum, Poland \\ 2) Upper Silesia Centre of Neurorehabilitation and Physiotherapy of Motor Organ Dysfunctions "MODERN-REH" in Mysłowice, Poland \\ F) Faculty of Health Sciences, Jagiellonian University Collegium Medicum, Poland \\ Rehabilitation Clinic, Faculty of Health Sciences, Jagiellonian University Collegium Medicum, Poland
}

\begin{abstract}
Introduction: The objective of this paper is to analyse the correlation between pain and the degree of disability, and the lesions shown on radiological examination of KOA.

Material and method: The study encompassed 31 female patients (42 knees) aged 51-70 years, with diagnosed idiopathic knee osteoarthritis. Medical history and analysis of previously performed x-ray scans were conducted. The history included questions regarding pain (VAS, WOMAC index) and the maximum marching distance, the presence of oedema and instability as well as disability in everyday life (WOMAC index). The radiological lesions were assessed using the Kellgren and Lawrence Grading Scale. Moreover, the widths of the joint spaces were measured.

Results: The patients' pain in everyday activities (WOMAC) showed a positive correlation with the presence of osteophytes ( $r=0.32$ ), and the intensity of the pain on the VAS correlated with the presence of joint osteophytes $(r=0.46)$ and with the elevation of the intercondylar eminence ( $r=0.32)$. The other disorders on the $x$-ray image did not correlate with the pain. Positive correlations were identified between the presence of oedema ( $r=0.57)$ and instability $(r=0.39)$, and the presence of lesions in the patellofemoral joint. The patients' disability in everyday activities (WOMAC) showed a negative correlation with the width of the joint spaces $(r<-0.34)$. However, no correlations were observed between the remaining $x$-ray lesions and the WOMAC index.

Conclusions: Only a small number of subjects showed a correlation indicating an interdependency between the painful sensations and the degree of disability versus the progression of radiographic lesions. Among the KOA risk factors, it is worth noting the presence of obesity which, in these studies, affected more than half of the female patients.

Key words: knee osteoarthritis, pain, disability, radiographic features.
\end{abstract}

ARTICLE INFO

PolHypRes 2016 Vol. 56 Issue 3 pp. 53 - 62

ISSN: $1734-7009$ elSSN: 2084-0535

DOI: $10.1515 /$ phr-2016-0020

Pages: 10, figures: 3 , tables: 3

page www of the periodical: www.phr.net.pl

Publisher

Polish Hyperbaric Medicine and Technology Society

\section{Original article}

Delivery date: $15.02 .2016 \mathrm{r}$.

Date of approval for print: 23.04.2016r. 


\section{INTRODUCTION}

The knee is the largest joint in the human body and one of the most important parts of our locomotor system. It is the degree of its degeneration that, to a significant extent, determines proper physical mobility and the level of pain experienced. The studies of knee osteoarthritis revealed that, in some cases, there are not any unambiguous relations like the one described above. This demonstrates that the level of pain experienced and the reduced mobility result not only from the osteoarthritis identified on the x-ray scan, but are also due to reasons, the identification of which has been attempted in the present paper.

According to the American College of Rheumatology (ACR), knee osteoarthritis (KOA) is a disturbance of the synthesis processes and a degradation of the articular cartilage and the subchondral bone layer [1]. It is one of the civilisation diseases and can affect one or more joints. Knee osteoarthritis (KOA) is the most common cause of physical disability affecting $15 \%$ of the population aged 65 or more [2]. It often occurs bilaterally, particularly in the idiopathic form. The major risk factors of idiopathic KOA include: age, sex, genetic factors, obesity, mechanical overload and smoking [3].

An essential role in the proper functioning of the knee joint is played by the articular cartilage, which is intended to minimise the friction during movement and absorb shocks. This is possible thanks to the high water content and the specific structure of the cartilage surfaces [4]. Chondrocytes are capable of synthesising specific components of the cartilage matrix (collagen (II, IX i XI) and aggrecans, as well as of producing specific proteases and degrading the matrix.

Under physiological conditions, there is a balance between these processes. Maintaining this balance is crucial for the cartilage to function correctly [5]. Once it is compromised and when the degenerative processes begin to prevail, the KOA may develop, thus leading to cartilage destruction, and the formation of osteophytes, geodes and subchondral bone sclerosis [2].

The main symptom of the KOA is arthralgia. The pain occurs during exertion, intensifies when the affected joint is moved and subsides at rest. It is usually difficult to be localised precisely. When the patellofemoral joint is involved, the pain primarily occurs during such activities as walking up and down the stairs (it results from high pressure of the patella against the femur during these activities); however, when the osteoarthritic lesions occur to a greater extent in the femoro-tibular joint, the most intense pain is felt while standing and walking. As time passes, the pain also occurs at rest (it may cause sleep disturbances).

The osteoarthritic pain comes from other joint structures due to the fact that the articular cartilage is not innervated. It may be caused by stretching the nerve endings located in the periosteum that covers the osteophytes, by inflammation of the synovial membrane or by microfractures in the subchondral areas of the bone. Additionally, the pain may result from: increased pressure within the marrow cavity, stretching the articular capsule, muscle contraction, enthesopathies or bursitis [6]. Other symptoms of the KOA include stiffness, oedema, instability, crepitation, limited mobility of the joint and muscle weakness.

\section{DIAGNOSTICS OF KNEE OSTEOARTHRITIS}

The traditional $\mathrm{x}$-ray is a commonly used standard in the diagnosis of the knee joint. It is customary to use two projections, namely the anteroposterior and the lateral, as well as the oblique one to visualise specific anatomical structures. Such x-rays are taken with the patient standing, to reveal instabilities in the joint and the actual widths of the joint space. This makes it possible to measure the distance between the bones and the joint space narrowing, as well as to confirm the presence of osteophytes, cysts and subchondral bone sclerosis (Fig. 1).

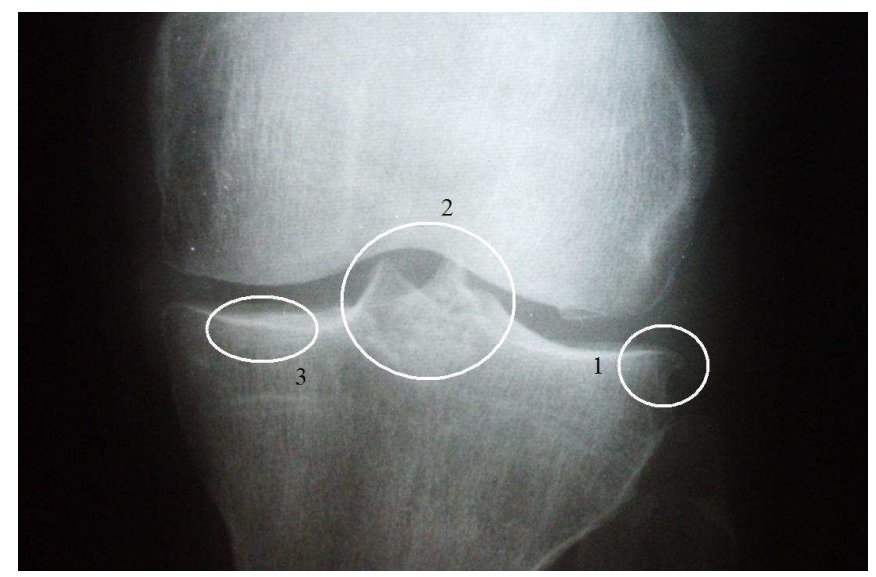

Fig. 1. Osteoarthritic lesions: a marginal osteophyte (1), elevation of the intercondylar eminence (2), subchondral bone sclerosis (3). Source: own elaboration. 
A standard procedure is to perform comparative scans of both knees at the same time on the same film (identical exposure and darkroom conditions). The radiological image obtained allows for early detection of subtle lesions in their initial stage [7]. Such a radiograph constitutes the basis for obtaining the first and most popular assessment of the progression of knee osteoarthritic lesions based on the Kellgren and Lawrence Grading Scale from 1957 presented in Table 1.

Kellgren and Lawrence Grading Scale [7]

\begin{tabular}{ll}
\multicolumn{1}{c}{ Kellgren and lawrence grading scale } \\
\hline Grade I & Doubtful lesions: marginal osteophytes, marginal significance \\
\hline Grade II & Marginal lesions: definite osteophytes, unaffected joint-space narrowing \\
\hline Grade III & Moderate lesions: mild joint-space narrowing \\
\hline Grade IV & Severe lesions: seriously damaged joint space with subchondral bone sclerosis \\
\hline Source: Own elaboration. &
\end{tabular}

Figure 2, on the other hand, presents the Kellgren and Lawrence Grading Scale, which was created from the female patients' radiographs.

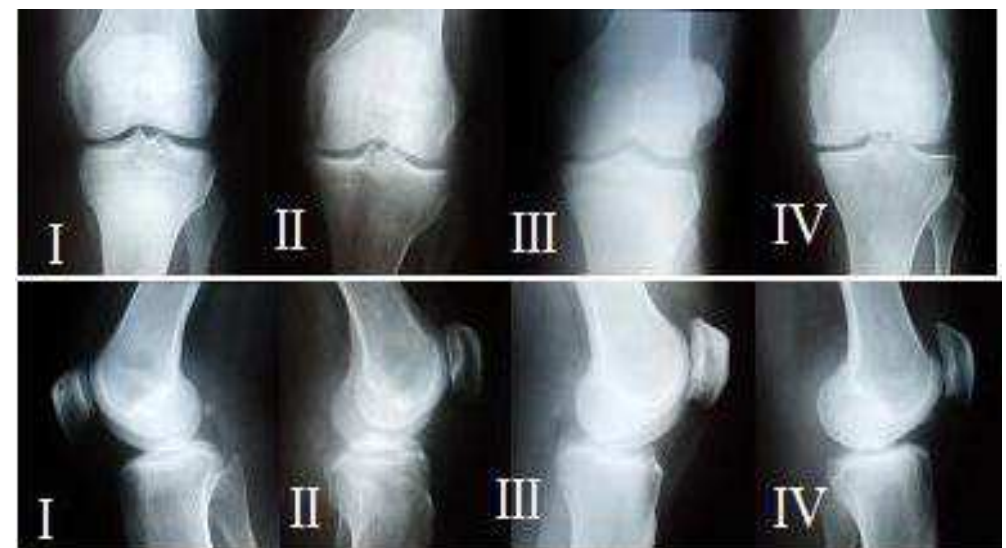

Fig. 2. The Kellgren and Lawrence Grading Scale created from the female patients' radiographs (from the left: I, II, III, IV degree). Source: own elaboration.

Practical evidence shows that the conclusions drawn on the basis of such a study are ambiguous in a large number of cases. This led to the determination of the objective of the present paper, which is to analyse the relations of pain and disability versus the state of knee osteoarthritis indicated on the basis of an $\mathrm{x}$-ray image.

\section{MATERIAL AND METHOD}

The studies encompassed patients at the "Krzeszowice" Rehabilitation Centre over the period from February 01, 2008 to June 31, 2008.

The study encompassed 31 female patients aged 51-70 years (mean: 60.26 SD 6.65), who suffered from idiopathic knee osteoarthritis. They had had their standing anteroposterior and lateral knee x-rays taken over a preceding period of not more than 6 months. The study group included 42 knees ( 22 right, 20 left). Eleven individuals had both their joints examined, while twenty patients - only one.

The group excluded patients with coxalgia, hip or knee joint endoprostheses, gout-induced arthritis, rheumatoid arthritis (RA), diabetes, neurological disorders and post-traumatic lesions. Medical history was taken of all the qualified individuals on the first day of the rehabilitation period, according to a survey questionnaire, and the subjects' knee joint $x$-ray images were evaluated. The survey consisted of questions concerning:

- $\quad$ pain (duration, intensity of the pain over the pastmonth and on day of the survey (rated on the VAS),

- the maximum distance of marching,

- the presence of oedema and instability in the knee,

- pain, stiffness and disability according to the WOMAC scale.

The WOMAC (Western Ontario and McMaster Universities) index is used to assess pain, stiffness, physical condition of the knee or the hip in osteoarthritis within the past 42 hours [8]. This study was based on the section referring to pain.

The intensity of pain was assessed on the Visual Analog Scale (VAS) at a 10-centimeter section bounded by a set of points: no pain (from the left) versus extreme pain (from the right). The patients were marking the value of pain while their medical history was being taken, as well as the maximum pain experienced over the preceding month [9].

The radiographs were assessed using the Kellgren and Lawrence Grading Scale. The assessing 
individual was the so-called "blinded rater" (not familiar with the complaint assessment surveys). The width of the medial and the lateral joint spaces, on the other hand, was measured at the narrowest point, in their middle part (Fig. 3).

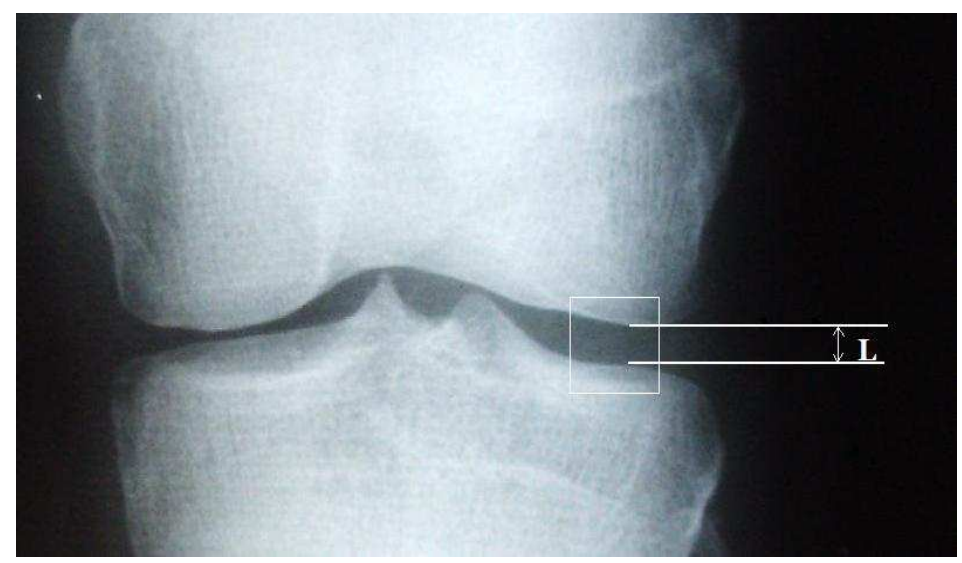

Fig. 3. The method of analysing the width of joint spaces on an x-ray based on the lateral joint space (L). Source: own elaboration.

A statistical analysis was performed using the Microsoft Office Excel 2007 spreadsheet and the Statistica 8 programme. The Excel spreadsheet was used to calculate mean values, minimums and maximums, standard deviations and percentage values, while the Statistica programme - to verify whether the distributions were within normal range and to calculate the Pearson's correlation coefficient for normal distributions and a statistical prognosis for the findings.

\section{TEST FINDINGS}

The mean BMI value amounted to $31.07 \mathrm{~kg} / \mathrm{m}^{2}$ (24.9-39.8 $\mathrm{kg} / \mathrm{m}^{2} ;$ SD 4.15). Only $5 \%$ of the female patients exhibited normal BMI values (18.5 - 24.9). The BMI value indicated that $33 \%$ of the female patients were overweight $(25.0$ - 29.9), $45 \%$ suffered from first degree obesity (30.0 - 34.9), and 17\% from second-degree obesity (35.0 - 39.9). Abnormalities in the BMI were observed in the total of $95 \%$ female patients, $62 \%$ of whom also had obesity [10].

The findings revealed a negative correlation between the duration of pain and the width of the medial joint space $(r=-0.41)$. A positive correlation was noticed between the duration of pain and the presence of lesions in the patellofemoral joint ( $\mathrm{r}=0.37)$. No correlation was reported between the duration of pain and the width of the lateral joint space, the progression of lesions according to the Kellgren and Lawrence Grading Scale, the presence of osteophytes and the sharpening of the intercondylar eminence (Table 2).

Tab. 2

Correlations between pain complaints and radiological lesions. The designated correlation coordinates are statistically significant with $\mathrm{p}<0.05 \mathrm{~N}=42$.

\begin{tabular}{|c|c|c|c|c|c|c|}
\hline & $\begin{array}{l}\text { Width of the } \\
\text { medial joint } \\
\text { space [mm] }\end{array}$ & $\begin{array}{l}\text { Width of the } \\
\text { lateral joint } \\
\text { space }[\mathrm{mm}]\end{array}$ & $\begin{array}{l}\text { Kellgren and } \\
\text { Lawrence } \\
\text { Grading Scale }\end{array}$ & $\begin{array}{c}\text { Involved } \\
\text { patellofem- } \\
\text { oral joint }\end{array}$ & $\begin{array}{c}\text { Osteophyte } \\
\text { presence }\end{array}$ & $\begin{array}{l}\text { Sharpening of } \\
\text { the } \\
\text { intercondylar- } \\
\text { eminence }\end{array}$ \\
\hline $\begin{array}{c}\text { Duration of } \\
\text { pain in years }\end{array}$ & $\begin{array}{c}r=0.41 \\
p=0.007\end{array}$ & $\begin{array}{c}r=0.02 \\
p=0.898\end{array}$ & $\begin{array}{c}r=0.24 \\
p=0.124\end{array}$ & $\begin{array}{c}r=0.37 \\
p=0.016\end{array}$ & $\begin{array}{c}r=0.18 \\
p=0.247\end{array}$ & $\begin{array}{c}r=0.19 \\
p=0.219\end{array}$ \\
\hline $\begin{array}{l}\text { Number of } \\
\text { painful days } \\
\text { over the past } \\
\text { month }\end{array}$ & $\begin{array}{l}r=-0.10 \\
p=0.512\end{array}$ & $\begin{aligned} r & =-0.06 \\
p & =0.713\end{aligned}$ & $\begin{array}{c}r=0.18 \\
p=0.260\end{array}$ & $\begin{aligned} r & =0.29 \\
p & =0.065\end{aligned}$ & $\begin{array}{c}r=0.02 \\
p=0.893\end{array}$ & $\begin{array}{c}r=0.15 \\
p=0.339\end{array}$ \\
\hline $\begin{array}{c}\text { VAS over the } \\
\text { past month } \\
{[\%]}\end{array}$ & $\begin{array}{l}r=-0.05 \\
p=0.728\end{array}$ & $\begin{array}{l}r=-0.05 \\
p=0.728\end{array}$ & $\begin{array}{c}r=0.08 \\
p=0.617\end{array}$ & $\begin{array}{c}r=0.10 \\
p=0.529\end{array}$ & $\begin{array}{c}r=0.46 \\
p=0.002\end{array}$ & $\begin{array}{c}r=0.32 \\
p=0.038\end{array}$ \\
\hline $\begin{array}{l}\text { VAS during } \\
\text { medical } \\
\text { history [\%] }\end{array}$ & $\begin{array}{c}r=0.16 \\
p=0.323\end{array}$ & $\begin{array}{c}r=0.01 \\
p=0.927\end{array}$ & $\begin{array}{l}r=-0.29 \\
p=0.061\end{array}$ & $\begin{array}{l}r=-0.08 \\
p=0.629\end{array}$ & $\begin{array}{c}r=0.12 \\
p=0.450\end{array}$ & $\begin{array}{c}r=0.02 \\
p=0.900\end{array}$ \\
\hline Pain (WOMAC) & $\begin{array}{l}r=-0.11 \\
p=0.490\end{array}$ & $\begin{array}{l}r=-0.21 \\
p=0.188\end{array}$ & $\begin{array}{c}r=0.02 \\
p=0.892\end{array}$ & $\begin{aligned} r & =0.20 \\
p & =0.197\end{aligned}$ & $\begin{array}{c}r=0.32 \\
p=0.036\end{array}$ & $\begin{array}{c}r=0.19 \\
p=0.233\end{array}$ \\
\hline
\end{tabular}


No correlation was found between the number of days in a month with knee pain and all the radiological parameters examined.

The analysis demonstrated positive correlation between the VAS value for the maximum pain over the past month and the presence of osteophytes $(r=0.46)$ and sharpening of the intercondylar eminence $(=0.32)$. No correlation was determined between the VAS value for the maximum pain over the past month and the knee joint space widths as well as between the progression of lesions according to the Kellgren and Lawrence Grading Scale and the involvement of the patellofemoral joint. Moreover, no correlation was found between the VAS value for assessing pain upon examination and the radiological lesions detected.

A positive correlation was also observed between the WOMAC value assessing the part concerning pain and the presence of osteophytes $(\mathrm{r}=0.32)$. However, no correlation was found between the remaining radiological parameters (the knee joint space widths, the progression of lesions according to the Kellgren and Lawrence Grading Scale, the involvement of the patellofemoral joint and the sharpening of the intercondylar eminence).

Table 3 presents the correlations between disability parameters and radiological lesions.

Tab. 3

\begin{tabular}{|c|c|c|c|c|c|c|}
\hline & $\begin{array}{l}\text { Width of the } \\
\text { medial joint } \\
\text { space }[\mathrm{mm}]\end{array}$ & $\begin{array}{l}\text { Width of the } \\
\text { lateral joint } \\
\text { space }[\mathrm{mm}]\end{array}$ & $\begin{array}{l}\text { Kellgren and } \\
\text { Lawrence } \\
\text { Grading Scale }\end{array}$ & $\begin{array}{l}\text { Involved } \\
\text { patellofem- } \\
\text { oral joint }\end{array}$ & $\begin{array}{l}\text { Osteop-hyte } \\
\text { presence }\end{array}$ & $\begin{array}{l}\text { Sharpening of } \\
\text { the } \\
\text { intercondylar- } \\
\text { eminence }\end{array}$ \\
\hline $\begin{array}{l}\text { Maximum } \\
\text { distance }[\mathrm{m}]\end{array}$ & $\begin{array}{l}\mathrm{r}=0,32 \\
\mathrm{p}=0,040\end{array}$ & $\begin{array}{l}r=0,03 \\
p=0,853\end{array}$ & $\begin{array}{l}r=-0,21 \\
p=0,179\end{array}$ & $\begin{array}{l}r=-0,22 \\
p=0,159\end{array}$ & $\begin{array}{l}r=-0,30 \\
p=0,052\end{array}$ & $\begin{array}{l}r=-0,26 \\
p=0,092\end{array}$ \\
\hline Oedema & $\begin{array}{l}r=-0,27 \\
p=0,082\end{array}$ & $\begin{array}{l}r=0,06 \\
p=0,719\end{array}$ & $\begin{array}{l}r=0,30 \\
p=0,053\end{array}$ & $\begin{array}{l}r=0,57 \\
p=0,000\end{array}$ & $\begin{array}{l}r=0,32 \\
p=0,041\end{array}$ & $\begin{array}{l}r=0,23 \\
p=0,150\end{array}$ \\
\hline Instability & $\begin{array}{l}r=-0,08 \\
p=0,619\end{array}$ & $\begin{array}{l}r=-0,05 \\
p=0,747\end{array}$ & $\begin{array}{l}r=0,2 \\
p=0,212\end{array}$ & $\begin{array}{l}r=0,39 \\
p=0,011\end{array}$ & $\begin{array}{l}r=0,05 \\
p=0,737\end{array}$ & $\begin{array}{l}r=0,11 \\
p=0,500\end{array}$ \\
\hline $\begin{array}{l}\text { Stiffness } \\
\text { (WOMAC) }\end{array}$ & $\begin{array}{l}r=-0,15 \\
p=0,330\end{array}$ & $\begin{array}{l}r=-0,35 \\
p=0,023\end{array}$ & $\begin{array}{l}r=0,02 \\
p=0,905\end{array}$ & $\begin{array}{l}r=-0,25 \\
p=0,104\end{array}$ & $\begin{array}{l}r=0,05 \\
p=0,740\end{array}$ & $\begin{array}{l}r=0,08 \\
p=0,624\end{array}$ \\
\hline $\begin{array}{l}\text { Disability } \\
\text { (WOMAC) }\end{array}$ & $\begin{array}{l}r=-0,38 \\
p=0,013\end{array}$ & $\begin{array}{l}r=-0,41 \\
p=0,007\end{array}$ & $\begin{array}{l}r=0,22 \\
p=0,154\end{array}$ & $\begin{array}{l}r=0,08 \\
p=0,614\end{array}$ & $\begin{array}{l}r=0,27 \\
p=0,079\end{array}$ & $\begin{array}{l}r=0,25 \\
p=0,103\end{array}$ \\
\hline
\end{tabular}

Source: Own elaboration.

Positive correlation was recorded between the maximum possible marching distance and the width of the medial joint space $(\mathrm{r}=0.32)$. However, no correlation was observed between the remaining radiological lesions. Positive correlations were found between the prevalence of oedema versus the presence of lesions in the patellofemoral joint $(\mathrm{r}=0.57)$ and the presence of osteophytes $(\mathrm{r}=0.32)$. No correlation, however, was determined between the presence of oedema and the widths of the knee joint spaces as well as between the progression of lesions according to the Kellgren and Lawrence Grading Scale and sharpening of the intercondylar eminence.

A positive correlation was found between the presence of instability and the involvement of the patellofemoral joint $(\mathrm{r}=0.39)$. No correlation was recorded between the presence of instability and the widths of the knee joint spaces as well as between the progression of lesions according to the Kellgren and Lawrence Grading Scale, the presence of osteophytes and sharpening of the intercondylar eminence. A negative correlation was identified between the WOMAC value assessing the part related to stiffness and the width of the lateral joint space $(r=-0.35)$. No correlation was found between the remaining radiological parameters.

Negative correlations were also present between the WOMAC value applying to the analysis of disability versus the width of the medial joint space ( $\mathrm{r}=-0.38)$ and the lateral joint space $(\mathrm{r}=-0.41)$. No correlation was reported between the WOMAC value assessing the disability-related part and the progression of lesions according to the Kellgren and Lawrence Grading Scale, the presence of lesions in the patellofemoral joint, the presence of osteophytes and the sharpening of the intercondylar eminence.

\section{DisCUSSION}

It was observed that the narrower the medial joint space in the knee was, the longer the pain lasted (in years). Longer duration of pain correlated with longer duration of high load being exerted on the damaged cartilage, which was subject to increasing degradation. Long duration of pain also increases the likelihood of lesions in the patellofemoral joint.

Different data were obtained from the studies in North Staffordshire, Great Britain. It was demonstrated that the longer the duration of complaints (pain, stiffness) was, the higher the progression of lesions on the Kellgren and Lawrence Grading Scale. The studies were conducted on 819 patients [11].

There was a correlation between the presence of osteophytes versus the value of knee pain on the VAS and the value of the pain-related WOMAC index. A similar correlation was identified between the sharpening of the intercondylar eminence and the knee pain value on the VAS. This suggests that there is a dependency between the progression of osteogenic lesions and the intensity of the pain experienced. 
The studies revealed no correlation between the joint space widths, the progression of the radiological lesions and the intensity of painful sensations on the VAS and in the pain-related section of WOMAC. A similar absence of correlations between the joint space widths and pain in the WOMAC index was recorded in the Scandinavian studies [12], and in Great Britain the progression of osteoarthritic lesions was found to have no influence on the intensity of pain on the VAS [13]. Studies in the USA revealed that the more advanced the radiological stages of the disease were, the greater the correlations between the x-ray lesions and pain [14].

It was shown that the narrower the medial joint space in the knee was, the shorter the possible distance of marching; however, no correlation was found in relation to the width of the lateral joint space. This may result from higher prevalence of valgus knee in idiopathic knee osteoarthritis. Apart from that, none of the other radiological parameters correlated with the length of the marching distance.

It was observed that the presence of lesions in the patellofemoral joint and the presence of marginal osteophytes increase the likelihood of oedema formation in the knee. These disorders result in the damage of the joint surface anatomy. Abnormal compression and friction lead to inflammatory conditions and, consequently, to oedema in the knee. The other components of x-rays images (width of joint spaces, progression of lesions on the Kellgren and Lawrence Grading Scale, sharpening of the intercondylar eminence) showed no correlation with the presence of oedema.

It was noted that the sensations of knee instability in the female patients were correlated with the presence of lesions in the patellofemoral joint. On the one hand, it may be linked to the occurrence of lesions in the patellofemoral joint as the KOA progresses, that is in the advanced stage of the disease. On the other hand, knee joint instability may lead to the occurrence of osteoarthritic lesions in the weakened joint. The other factors shown in the radiological examination did not correlate with the occurrence of instability.

The studies demonstrated that the sensation of stiffness increased with the reduction of the lateral joint space, while no correlation between these two factors was identified in Scandinavia [12]. This discrepancymay result from the different size of the study groups, with the Scandinavian one being almost five times greater and including both females and males. Other radiological parameters examined did not correlate with the sensation of stiffness.

A correlation was found between the width of the joint spaces in the knee and the WOMAC index for disability. The narrower the spaces, the more difficult it is to bend the knee and, therefore, function in everyday life. Different study results - or no correlation - were obtained in Scandinavia [12]. Other radiological parameters (the progression of lesions according to the Kellgren and Lawrence Grading Scale, the presence of lesions in the patellofemoral joint, the presence of osteophytes and the sharpening of the intercondylar eminence) demonstrated no correlation with functional disturbances.

\section{Conclusions}

1. On the basis of the studies conducted, it can be concluded that there is only a relatively narrow range of correlations provingthe interdependency between pain and disability, and the progression of radiographic lesions.

2. It was confirmed that some of the pains and marching distance limitations show no direct relation with the KOA risk factors recorded on the $\mathrm{x}$-ray scan.

3. The analysis of the existing correlations suggests a hypothesis that, in many cases, the KOA may be caused by obesity, which was identified in more than half of the female patients examined.

4. Attention should be drawn to the differences in the results of some studies conducted by Polish and foreign scientists, which should be subject to separate analysis.

\section{BIBLIOGRAPHY}

1. Tuchocka-Piotrowska A. Możliwości farmakoterapii w chorobie zwyrodnieniowej stawów. Przewodnik lekarza 2007; 3 , p. 60-71 [The possibility of pharmacotherapy in osteoarthritis];

2. Wierusz-Kozłowska M, Markuszewski J. Choroba zwyrodnieniowa stawów. [in:] W. Marciniak, A. Szulc. ed. Wiktora Degi Ortopedia i Rehabilitacja. II wyd., PZWL: Warszawa, 2006, p. 274-289 [Osteoarthritis];

3. Arden N, Nevitt MC. Osteoarthritis: Epidemiology. Best Practice \& Research, Clinical Rheumatology, 2006, 20, I, p. 3-25;

4. Ciszek B. Morfologia i funkcja chrząstki stawowej. ActaClinica; 2001, 1, 1 [The morphology and function of articular cartilage];

5. Malejczyk J.Budowa i immunologia tkanki chrzęstnej. ActaClinica; 2001, 1, p.15-22 [Construction and immunology cartilage];

6. Szechiński J. Ból w chorobach reumatycznych. [in:] J. Dobrogowski, J. Wordliczka ed. Medycynabólu, I Wyd. PZWL: Warszawa, 2004, p.300309 [The pain in rheumatic diseases]:

7. Bruszewski J, Ziemiański A. Układ kostno-mięśniowy. [in:] B. Pruszyński ed. Radiologia. Diagnostyka obrazowa, II Wyd. PZWL: Warszawa, 2005, p.383-433 [Osteo-muscular system];

8. Petersson I, Boegard T, Saxne T, et al. Radiographic osteoarthritis of the knee classifield by Ahlbäck and Kellgren\& Lawrence systems for the tibiofemoral joint in people aged 35-54 years with chronic knee pain, Annals of the rheumatic diseases, 1997; 56;

9. Racewicz A, Badurski J. Choroba zwyrodnieniowa stawów (OA)- klasyfikacja, kryteria diagnostyczne, ocena kliniczna przebiegu choroby i leczenia w próbach klinicznych, wymogi techniczne wykonywania zdjęć radiologicznych. Postępyosteoartrologii 1996, 8, p.11-38 [Osteoarthritis $(\mathrm{OA})$ - classification, diagnostic criteria, assessment of clinical course of disease and treatment in clinical trials, the technical requirements for taking radiological pictures];

10. Baranowska B, Krzyżanowska-Świnarska B. Zaburzenia odżywiania. [in:] A. Szczeklik ed. Choroby wewnętrzne, Medycyna Praktyczna: Kraków 2005, p.1222-1225 [Eating disorders];

11. Ducan A, Peat G, Thomas E, Hay E, McCall E, Croft P.Symptoms and radiographic osteoarthritis: not as discordant as they are made out to be? Annals of the rheumatic diseases 2007; 66, p. 10-14;

12. Bruyere O, Honore A, Rovati L, Giacovelli G, Henrotin Y, Seidel L, Reginster J. Radiologic features poorly predict clinical outcomes in knee osteoarthritis. Scandinavian Rheumatology Research Foundation, 2002; 31, p. 13-16;

13. Barker K, Lamb S, Toye F, Jackson S, Barrington S. Association between radiographic joint space narrowing, function, pain and muscle power in severe osteoarthritis of the knee. Clinical Rehabilitation, 2004; 18, p. 793-800;

14. Williams D, Farrell M, Cunningham J, GracelyR, Ambrose K, Cupps T, Mohan N, et al. Knee pain and radiographic osteoarthritis interact in the prediction of levels of self-raported disability. Arthritis \& Rheumatism 2004; 51 (4), p. 558-561; 


\section{Dr Grzegorz Mańko}

Zakład Ergonomii i Fizjologii Wysiłku Fizycznego,

Wydział Nauk o Zdrowiu UJ CM,

Grzegórzecka 20, 31-531 Kraków

Tel: 502-052-280

e-mail: mankofizjo@gmail.com 